\title{
Rolling resistance evaluation of winter tyres on in-service road surfaces
}

\author{
Tiago Vieira* \\ tiago.vieira@vti.se
}

Swedish National Road and Transport Research Institute (VTI)

Olaus Magnus vaeg, 35

Linkoeping, SE-58195

Sweden

\author{
Department of Building Materials \\ KTH Royal Institute of Technology \\ SE-10044, Stockholm \\ Sweden
}

\author{
Ulf Sandberg \\ ulf.sandberg@vti.se
}

Swedish National Road and Transport Research Institute (VTI)

Olaus Magnus vaeg, 35

Linkoeping, SE-58195

Sweden

Sigurdur Erlingsson

sigurdur.erlingsson@vti.se

Swedish National Road and Transport Research Institute (VTI)

Olaus Magnus vaeg, 35

Linkoeping, SE-58195

Department of Building Materials 


\title{
KTH Royal Institute of Technology \\ SE-10044, Stockholm \\ Sweden
}

\author{
Faculty of Civil and Environmental Engineering \\ University of Iceland \\ IS-107, Reykjavik \\ Iceland
}

*Corresponding author

Submitted for consideration for publication in the journal Tire Science and Technology.

ABSTRACT: Rolling resistance, the energy dissipated due to the rolling movement of a pneumatic tyre over a surface, is a relevant factor that should be considered when aiming at a more energy efficient road infrastructure as well as for reducing $\mathrm{CO}_{2}$ emissions. The energy dissipation, as a result mainly of hysteretic losses, is dependent on the tyre, on the road surface, and operating temperature, among other factors. In this paper, 50 different tyres of five different types (all season tyres, summer tyres, winter tyres without studs, winter tyres with studs and winter tyres with hard particles) were evaluated with respect to rolling resistance on two different road surfaces, at three different test speeds and different states of tyre wear. In addition to the full-scale field tests, a drum facility was used to evaluate rolling resistance of the same tyres in a more controlled environment. This resulted in more than 500 measurements that were analysed in this paper. Earlier, no data regarding rolling resistance of studded winter tyres have been published and there have been very few studies, if any, comparing measurements on drums with measurements on road pavements. In the field, rolling resistance was significantly 
depending on tyre type, and many tested tyres performed differently on the two surfaces. No significant correlation was found between labelled tyre values and rolling resistance measured on roads, nor between rolling resistance measured on roads and on a drum facility. Better correlations were found between labelled tyre values and our own drum results. This calls for a review of the relevance of the energy labelling procedure.

KEY WORDS: rolling resistance, tyre, pavement, surface, winter

\section{Introduction}

Rolling resistance affects fuel consumption of road vehicles and is, therefore, an important aspect that should be considered to achieve a more energy efficient road infrastructure. Moreover, rolling resistance also affects the emission of exhaust gases like $\mathrm{CO}_{2}$ and, therefore, it is also a climate change issue. When implementing pavement selection and maintenance strategies, it is relevant to include rolling resistance in the decision-making criteria in order to find the most cost-effective and environmentally friendly solution [1]. The impact of rolling resistance on fuel consumption can be expressed by the return factor, which is the ratio between the relative improvement in fuel economy resulting from a reduction in rolling resistance. Typical values for passenger cars are between 8 and $20 \%$ [2].

An accurate estimation of rolling resistance is especially important when it comes to electric vehicles as it is fundamentally important to estimate the vehicle's energy consumption and range before having to recharge [3]. 
A pneumatic tyre rolling on a road surface will dissipate energy due to its materials and construction as well as the interaction with the road surface, resulting in rolling resistance. Hysteretic energy dissipation accounts for up to $95 \%$ of the rolling resistance as the tyre structure is cyclically deformed to establish contact with the road surface [2]. The cyclical tyre deformation leads to bending of the crown region, sidewalls and bead, compression of the tread and shearing of the tread and sidewall regions. This ultimately leads to energy dissipation and rolling resistance losses [2].

Some factors that affect rolling resistance, other than the tyre itself, are the road surface texture, unevenness and stiffness, air resistance, wind, and inertial resistance, among others. An example of how such different terms can be modelled and how they contribute to the vehicle energy dissipation can be found in [4]. Additionally, the presence of water, ice or snow on the road surface is also relevant as this will affect rolling resistance, not only as the tyre has to remove them to establish contact with the road surface but also as they affect the tyre temperature, which will directly affect the hysteretic dissipation mechanisms [5].

When considering snow, ice and low operating temperatures, in countries with severe winter climates, such as Sweden, Norway, Finland, Iceland, Russia, Canada and some states in the USA, studs mounted in the tyre tread are used in order to improve friction. These studs, that may number up to $80-200$ per tyre, have the disadvantage that they dramatically increase the wear on the road surface and subsequent spread of fine particles in the air, and also that they increase noise emission. Consequently, the safety benefits are compromised by environmental, health and economic effects [6], which makes the acceptance of studded winter tyres arguable and often questioned by authorities and environmental interest groups. A cost-benefit assessment 
of the use of studded tyres can be found in [7], in which it was concluded that at least in southern Sweden, studded tyres do not involve significant net benefits.

The knowledge about rolling resistance of winter tyres compared to other tyres is still limited. Not many scientific publications are available, and when considering studded tyres, there is practically no information available. This is most probably because testing studded tyres poses special operational difficulties and since such tyres are allowed only in a few and rather sparsely populated regions in the world. For instance, testing studded tyres in a drum as most other tyres are tested on, would damage the drum surface itself and, consequently, this way of measuring rolling resistance is not possible for studded tyres.

The aim of this study was to evaluate the rolling resistance of several types of tyres, on different in-service road surfaces, different speeds and the tyre's state of wear. The focus was laid on winter tyres, both with and without studs. For comparison purposes a few summer and allweather tyres were included in the tests.

Additional analyses were made regarding the tyre labelled values (required by EU legislation) in comparison with the measured rolling resistance values measured both on the inservice road surfaces and on the drum. Different tyre categories were analysed, including all season tyres (AS), summer tyres (SU), winter tyres without studs (WI), winter tyres with studs (WIST) and winter tyres with hard particles baked into the tread rubber (WIGD). This resulted in more than 500 measurements from roads and more than 50 measurements on a drum that were analysed to provide a comprehensive analysis of the differing energy dissipation for the different tested tyres under different test conditions. This allowed an evaluation of how the tyres responded to different road surfaces, test speeds and different states of wear. 


\section{Rolling resistance as an energy dissipation mechanism}

Rolling resistance is the effort required to keep a tyre rolling at a given speed. It is a result of mechanical energy converted into heat for a rolling tyre moving over a given pavement length [2]. Energy loss arises from the tyre being subjected to cyclic loading as its surface deforms itself to form the contact patch. This leads to bending of the crown, sidewalls and bead areas, compression of the tread, and shearing of the tread and sidewalls. The crown region contains the belt which behaves as an inextensible and incompressible layer. The tyre also contains viscoelastic layers, like the tread and the liner. When the crown is subjected to bending deformations, the inner and outer layers that surround the belt will be subjected to tension and compression cycles, which substantially contribute to rolling resistance losses. Additional energy losses take place in the sidewall and bead region that combined account for approximately $30 \%$ of energy losses during rolling [2]. This generates a travelling wave which will also dissipate energy. When a tyre is loaded and the crown is flattened to form the contact patch, this imposes deformations in the sidewall and bead regions. This bending deformation results in tension and compression for the inner and outer layers, similar to the mechanism described in the crown. A more comprehensive discussion on footprint mechanics has been presented by Gent and Walter [2].

In this paper, rolling resistance is expressed by the so-called rolling resistance coefficient, $\mathrm{RRC}$, which is defined as the ratio between the magnitude of the rolling resistance force, $F_{R}$, and the magnitude of the normal force applied to the tyre, $N$. This results, therefore, in the dimensionless rolling resistance coefficient, as shown in equation (1). This definition is applicable here, given the test conditions. For higher test speeds, this coefficient becomes speed dependent, as indicated in [8]. 


$$
\mathrm{RRC}=\mathrm{F}_{\mathrm{R}} / \mathrm{N}
$$

Rolling resistance is affected not only by the test speed, although this influence is rather weak at speeds below $100 \mathrm{~km} / \mathrm{h}$, but much more significantly by the tyre temperature, and even the non-linear behaviour of the tyre structure, which includes the Mullins and Payne effects, that result in the tyre rubber softening at high and low strains, respectively [2]. Additionally, the road surface also has a significant effect on rolling resistance, as indicated in [4, 9-11]. Previous investigations in Europe have focused on optimizing road infrastructure in order to minimize rolling resistance, such as [12] and project ROSE (www.rose-project.dk) and indicate that it is possible to reduce rolling resistance by optimizing road surfaces and pavement design. Moreover, the use of surface optimization techniques such as grinding has also indicated positive results in reducing rolling resistance. By using a horizontal grinding technique in some test sections in Sweden a rolling resistance reduction of up to $15 \%$ was achieved [13].

Typically, RRC values for car tyres range between 0.005 and 0.020 . Then it is practical to multiply the values by 100 , which means that the dimensionless RRC (N/N) will be expressed in \% (of 1.00). In this article, the RRC is expressed in \% (of 1.00); i.e. the original RRC:s are multiplied by 100 .

Given that one of the major challenges for European road networks now is to provide efficient transportation with proper safety levels, considering public health and environmental impacts [14], rolling resistance is a relevant pavement functional property that should be addressed.

\section{Measurements methods and measured tyres}

\subsection{General information}


A total of 50 different tyres were tested regarding the rolling resistance on two different road test sections at three different testing speeds as well as on a drum facility. For each tyre, test section and speed, a minimum of two and up to four runs were carried out, leading to more than 500 rolling resistance measurements in order to characterize how the energy efficiency of tyres differs. The measurements were performed in two measurement campaigns, the first between February and April of 2015 and the second between March and April of 2016. Rolling resistance measurements carried out on the drum were taken with two slightly different procedures and on two drum surfaces, namely: (i) ECE R117 - SMA 8, (ii) ECE R117 - Safety Walk (sand paper), and (iii) TUG procedure - SMA 8. The ECE R117 is the Regulation 117 [16], which specifies how tyre rolling resistance shall be measured according to EU Regulation EC1222-2009 on tyre labelling. The TUG procedure is a slightly modified procedure used by TUG which TUG considers having certain advantages [15]. Essentially, it implies using a lower load and inflation pressure that would be more common on vehicles operating in real traffic; being the same for all the car tyres irrespective of their load index.

In addition, the road surface texture was evaluated, as well as tyre/road noise performance of the same tyres using the Close Proximity method (CPX) in accordance with the ISO 11819-2 [16]. The noise results are published in another article by the same authors [17].

\subsection{Tested Tyres}

There are essentially three different types of winter tyres in Europe for passenger cars:

- winter tyres optimized for central-European or similar climates

- winter tyres optimized for north-European or similar climates, and 
- studded winter tyres (usually also optimized for north-European or similar climates).

In this text, they are referred to as "European winter tyres", "Nordic winter tyres" and "Studded winter tyres", respectively. Additionally, there is a tyre category called "all-season", which is a compromise between the common summer tyres and winter tyres. Furthermore, there is a special winter tyre design which is essentially optimized for northern climates but has silicium carbide granules evenly mixed into the rubber compound of the tyre tread. This is intended to provide a frictional performance somewhat similar to that of studded tyres. Such tyres were also tested in this project. They were developed in Iceland using retreaded tyres and are marketed in the Nordic countries as well as (previously) in North America. In this paper, they are referred to as "Green Diamond" tyres, referring to their brand name. The different tyre categories presented in this text, as well as the respective designations used further in this text, are presented in Table 1 and Table 2 . The tyre manufacturer and model information are not directly shown in this publication, as the aim of this paper is not to compare different manufacturers, nor different models. Therefore, each one of the 16 different manufacturers received a random designation from M1 up to M16. However, it is noted that the selection included major winter tyre manufacturers, such as Continental, Goodyear, Michelin, Nokian, among others.

TABLE 1 - Tested tyres categories, designations, descriptions and the respective number of samples. 


\begin{tabular}{|c|c|c|c|}
\hline Tyre Category & $\begin{array}{c}\text { Designati } \\
\text { on }\end{array}$ & AS & A compromise between summer and winter \\
All-season & SU & Tyres used in summer conditions only & $\begin{array}{c}\text { Number of } \\
\text { samples }\end{array}$ \\
\hline Summer & WI & $\begin{array}{c}\text { Tyres with no studs or hard particles in the } \\
\text { tyre tread }\end{array}$ & 24 \\
\hline Winter & WIGD & Tyres with hard particles in the tyre tread & 2 \\
\hline $\begin{array}{c}\text { Winter - Green } \\
\text { Diamond }\end{array}$ & WIST & Tyres with studs in the tyre tread & 12 \\
\hline Winter - Studded & &
\end{tabular}

TABLE 2 - Overview information about the tested tyres, including type and size. The manufacturers have been anonymized as the objective is to have a representative sample and not to compare different manufacturers.

\begin{tabular}{|c|c|c|c|c|c|c|c|}
\hline $\begin{array}{c}\text { Tyre } \\
\text { Number } \\
\end{array}$ & Type & Manufacturer & Size & $\begin{array}{c}\text { Tyre } \\
\text { Number } \\
\end{array}$ & Type & Manufacturer & Size \\
\hline 1 & AS & M3 & 195/60R15 & 26 & WI & M8 & 195/60R15 \\
\hline 2 & AS & M11 & 195/60R15 & 27 & WI & M8 & 195/60R15 \\
\hline 3 & AS & M5 & 195/60R 15 & 28 & WI & M4 & 185/60R15 \\
\hline 4 & AS & M4 & 195/60R15 & 29 & WI & M2 & 195/60R15 \\
\hline 5 & SU & M13 & 195/65R15 & 30 & WI & M2 & 195/60R15 \\
\hline 6 & SU & M13 & 195/65R15 & 31 & WI & M2 & 205/55R 16 \\
\hline 7 & SU & M13 & 195/65R15 & 32 & WI & M10 & 205/55R16 \\
\hline 8 & SU & M4 & 195/60R15 & 33 & WI & M2 & 205/55R16 \\
\hline 9 & SU & M4 & 195/60R15 & 34 & WI & M2 & 205/55R16 \\
\hline 10 & SU & M9 & 195/60R15 & 35 & WI & M2 & $205 / 55 \mathrm{R} 16$ \\
\hline 11 & SU & M10 & 205/55R 16 & 36 & WI & M10 & 205/55R16 \\
\hline 12 & SU & M10 & 195/60R15 & 37 & WIGD & M15 & $185 / 65 \mathrm{R} 15$ \\
\hline 13 & WI & M12 & 195/60R15 & 38 & WIGD & M15 & 185/65R15 \\
\hline 14 & WI & M10 & 195/60R15 & 39 & WIST & M14 & $185 / 65 \mathrm{R} 15$ \\
\hline 15 & WI & M10 & 195/60R15 & 40 & WIST & M16 & 185/65R15 \\
\hline 16 & WI & M6 & 195/60R15 & 41 & WIST & M16 & $185 / 65 \mathrm{R} 15$ \\
\hline 17 & WI & M6 & 195/60R15 & 42 & WIST & M7 & 185/60R15 \\
\hline 18 & WI & M4 & 195/60R15 & 43 & WIST & M7 & 185/60R15 \\
\hline 19 & WI & M4 & 195/60R15 & 44 & WIST & M1 & 185/65R15 \\
\hline 20 & WI & M2 & 195/60R15 & 45 & WIST & M2 & 195/60R15 \\
\hline 21 & WI & M14 & 185/60R16 & 46 & WIST & M2 & 195/60R15 \\
\hline 22 & WI & M14 & 185/60R15 & 47 & WIST & M4 & $185 / 65 \mathrm{R} 15$ \\
\hline 23 & WI & M2 & 185/65R15 & 48 & WIST & M9 & 185/65R15 \\
\hline 24 & WI & M2 & 185/65R15 & 49 & WIST & M2 & 195/60R15 \\
\hline 25 & WI & M9 & 195/65R15 & 50 & WIST & M2 & 195/60R15 \\
\hline
\end{tabular}


The winter tyres without studs (WI) are further divided into central European and northern European (the latter sometimes referred to as "Nordic") in this text due to the different optimization for different operational climates, as previously indicated. The summer tyres tested here were used as reference, as well as the reference tyre SRTT, the standard reference tyre according to ASTM 2493:14 [18].

The tyres listed here were all tested in new condition, though after a run-in process of 100 $\mathrm{km}$ and a warm-up process of about 15 minutes prior to each measurement. A small sample of four tyres was tested in both new and used conditions as well. The used conditions correspond to the average use for two winter seasons, and therefore resulted in both chemical and mechanical ageing of the tested tyres.

\subsection{Tyre load and inflation pressure}

The tested tyres were loaded in accordance with ECE regulation R117 [19] leading to a load of $408 \mathrm{~kg}$ for the measurements. Inflation pressure was adjusted in accordance with the specifications in ECE R117 leading to $180 \mathrm{kPa}$. Air, road and tyre surface temperatures were measured simultaneously with the rolling resistance measurements. They were similar to typical Swedish winter and early spring temperatures.

\section{$3.4 \quad$ Tested Road Surfaces}

Two road surfaces were used to evaluate the different tyre performances. One of the surfaces was a so-called DAC 16 (Dense Asphalt Concrete with maximum aggregate size 16 $\mathrm{mm}$ ) on an in-service road near Gdansk, in Poland. This surface was selected as its texture is similar to the SMA 16 road surface, which is the dominating surface on Swedish highways. The other surface was an SMA 8 (Stone Mastic Asphalt with maximum aggregate size $8 \mathrm{~mm}$ ), also on 
an in-service road near Gdansk, in Poland. This surface was selected in order to serve as a proxy for the surface used when testing tyres in accordance with EU regulations on tyre noise limits and noise labelling [20].

The reason why two surfaces were used was that the DAC 16, which resembles the texture of a Swedish SMA 16, would classify tyres representative of Swedish highway traffic, and the SMA 8 was included since it resembles the ISO 10844 surface of the original specification (1994), which was still in formal use in 2016 when the last measurements were made. ISO 10844 test tracks are used for noise labelling measurements, but not for rolling resistance measurements. However, SMA 8 pavements are common in Europe; thus, it was justified to use it also for rolling resistance measurements.

Both surfaces had their textures characterized by the Mean Profile Depth (MPD) in accordance with ISO 13473-1 [21] and by the International Roughness Index (IRI) in accordance with SS-EN 13036-5 [22] The surface characterization was performed by VTI's Road Surface Texture measurement vehicle in June of 2015. The results are presented in Table 3.

TABLE 3 - Tested pavement surfaces and the respective MPD and IRI values.

\begin{tabular}{|c|c|c|c|}
\hline $\begin{array}{c}\text { Pavement type in European } \\
\text { terminology }\end{array}$ & $\begin{array}{c}\text { Corresponding } \\
\text { Swedish pavement } \\
\text { type }\end{array}$ & $\begin{array}{c}\text { Average MPD } \\
{[\mathrm{mm}]}\end{array}$ & $\begin{array}{c}\text { Average IRI } \\
{[\mathrm{mm} / \mathrm{m}]}\end{array}$ \\
\hline SMA 8 (proxy for ISO 10844) & ABS 8 & 0.78 & 1.0 \\
\hline DAC 16 $(\approx$ SMA 16) & ABS 16 & 1.09 & 2.1 \\
\hline
\end{tabular}

It should be stressed that studded winter tyres are not allowed in Poland and this certainly affects the surface characteristics [23]. The objective when selecting the test surfaces here was, however, not to compare wear processes. The idea was to use surfaces that were representative of the tests performed here and use them as "reference" surfaces. As a consequence, by specifying 
"reference" road surfaces and performing the necessary temperature corrections, it was possible to compare how different tyres will perform in central or north European winter climate, which was the objective of this study.

\subsection{Rolling resistance measurements}

To evaluate rolling resistance two different techniques were used, namely measurements on roads with a trailer and measurements in laboratory conditions with a drum. All the results presented here are expressed as a Rolling Resistance Coefficient, RRC [\%]. This means that the energy dissipation is represented as a force opposing the wheel's movement and the RRC is obtained by dividing this force by the normal force applied on the wheel.

\subsection{Rolling resistance on road}

The rolling resistance measurements were performed by the Gdansk University of Technology (TUG) using the measuring trailer shown in Figure 1. The measurement procedures follow the recommendations of the project ROSANNE (http://rosanne-project.eu/). The construction details are shown in Figure 2. More information regarding this measurement equipment can be found in [24]. As the energy dissipation due to rolling resistance increases, $\theta$ will also increase. Rolling resistance was therefore measured in this construction setup by evaluating the angle $\theta$. The ballast consists of weights used to provide the desired test tyre load. By patented mechanisms, the trailer system compensates for road inclination, longitudinal acceleration and vibrations. Additionally, the system is protected by an enclosure to reduce aerodynamic drag. The enclosure was partially removed in Figure 1 to allow better visualisation. More details about the construction, including the compensations mechanism for inclination and calibration of the measurement trailer can be found in [25]. 
The selected test speeds were 50 and $80 \mathrm{~km} / \mathrm{h}$, and a minimum of three runs were made in each test condition. All tyres were tested at $80 \mathrm{~km} / \mathrm{h}$ and some tyres were tested at $50 \mathrm{~km} / \mathrm{h}$. A reduced number of measurements were further performed at $30 \mathrm{~km} / \mathrm{h}$ and are presented and discussed later in this text.

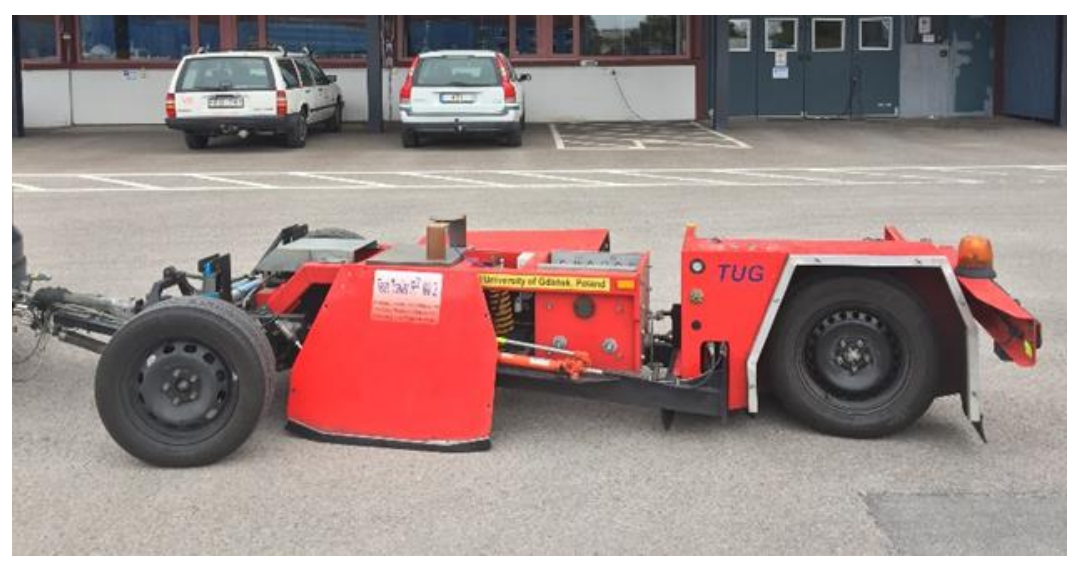

FIGURE 1 - The Rolling resistance measurement trailer by TUG.

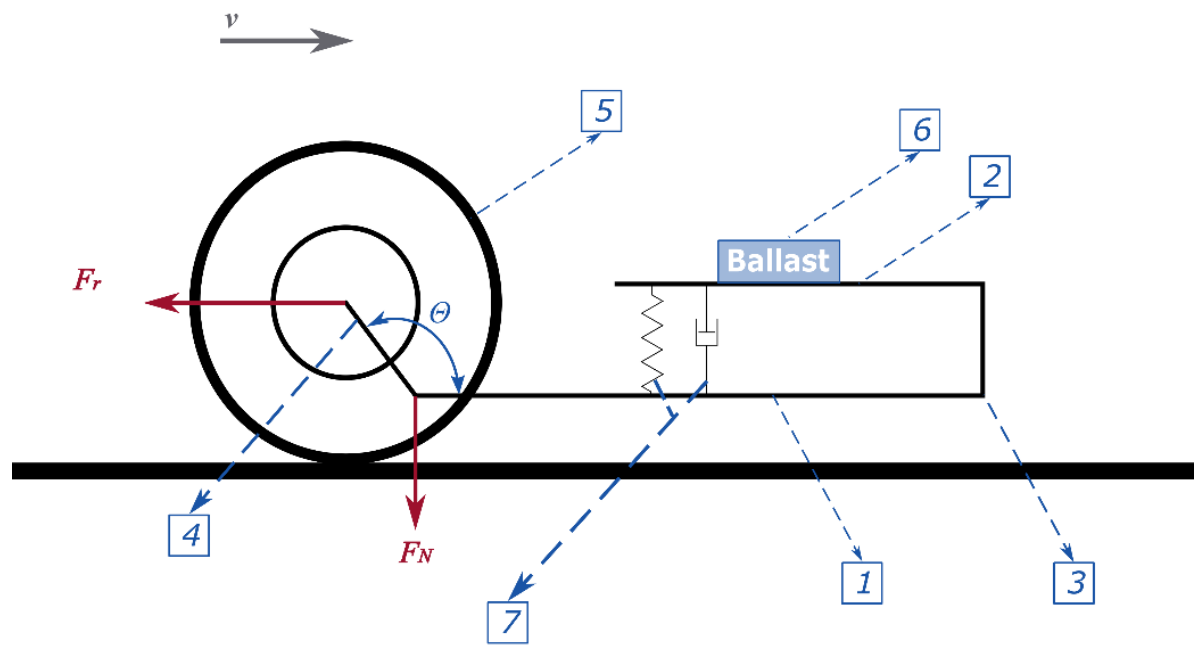

FIGURE 2 - TUG's Rolling resistance measurement trailer - construction details (supporting front tyres not shown). (1) horizontal arm that connects front and rear suspension systems, (2) horizontal arm that supports the ballast (6), (3) front wheels position, (4) pivoted arm equipped with the test wheel hub, (5) tested tyre, (6) ballast, and (7) suspension element for load transfer between (2) and (1). 


\subsection{Rolling resistance on drum}

A drum having a diameter of $1.7 \mathrm{~m}$ was used to evaluate rolling resistance in laboratory conditions at the TUG. All drum tests were carried out at a speed of $80 \mathrm{~km} / \mathrm{h}$. It had two surfaces adjacent to each other: one replica of an SMA 8 pavement and one sand-paper surface by $3 \mathrm{M}$ with brand name "Safety Walk".

\subsection{Normalization to the reference temperature}

All measurement results have been normalized to a reference air temperature of $10{ }^{\circ} \mathrm{C}$, in order to allow a fair comparison of the test results. Although air, road and tyre temperatures were measured, only air temperatures were used for normalization. The reference temperature of $10{ }^{\circ} \mathrm{C}$ was chosen, as opposed to the $25{ }^{\circ} \mathrm{C}$ reference temperature which is often used in other cases since it is rather similar to the average temperature during the measurements and thus, minimizes the corrections. Additionally, as winter tyres are optimized for lower operational temperatures, a lower reference temperature was desirable. The correction procedure described in [26] was used. The corrections were all within the range $-0.07 \%$ and $+0.08 \%$ for rolling resistance coefficient RRC (equal to less than $3 \%$ of the measured RRC values). The reason for this correction was that temperatures were within +6 and $+16^{\circ} \mathrm{C}$ during these measurements.

\section{Results}

\subsection{Introduction}

Data consistency was checked first and is presented in Figure 3. The data analysis was then carried out, initially by separating the results into different tyre categories and for different speeds. See further section 4.2. 
Figure 4 shows the rolling resistance coefficient for all tyre types at the test speeds of 50 and $80 \mathrm{~km} / \mathrm{h}$. The figure indicates that, even though the mean values differed by up to about 0.25 $\%$, there was significant overlap between the tyre categories at both tested speeds. Furthermore, the dispersion varied for each category; the highest dispersion was observed for the winter tyres category. The breakdown into different test speeds did not result in major differences, which was expected, given that the tested speeds are below $100 \mathrm{~km} / \mathrm{h}$, as discussed in section 2 .

\subsection{Data consistency check}

The results of the trailer measurements presented in the later sections do not show any strong signs of consistent results or good correlations. Therefore, we have explored the correlations between a couple of data sets that should show good correlations if the measurements have low uncertainties. If the uncertainties are high the correlations should be low. To check this, we selected the data set for tyres measured at both 50 and $80 \mathrm{~km} / \mathrm{h}$ and studied the correlations between these measurements. They were done on slightly different parts of the test sections, where there might be some minor texture and unevenness variations; first at one speed and some minute(s) later at the other speed. Temperature differences were neglegible between these measurements. Essentially, these measurements are independent. The results are shown in Figure 3. 


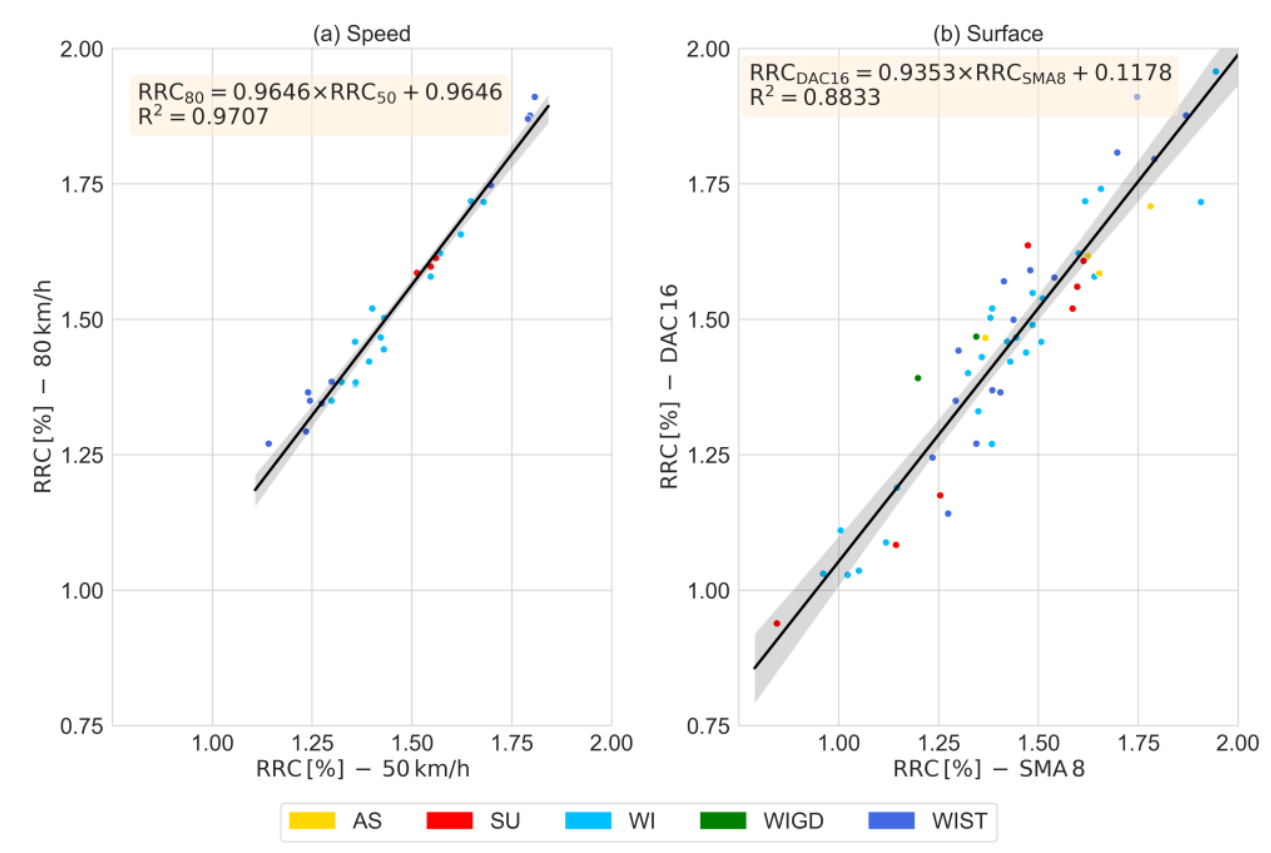

FIGURE 3 - Measured RRC results at $50 \mathrm{~km} / \mathrm{h}$ vs $80 \mathrm{~km} / \mathrm{h}$ for all tyres and speeds for which measurements were made at both speeds, and the corresponding linear regression equation and the respective coefficient of determination (a) and the measured RRC for each pavement surface for all tyres and all speeds where measurements were carried out on both surfaces and the respective coefficient of determination (b). The gray shaded region indicates the $95 \%$ confidence intervals for the linear regressions.

As previously discussed in this text, the speed influence on the rolling resistance coefficient is expected to be small as the tested speeds were below $100 \mathrm{~km} / \mathrm{h}$. Some deviation of results obtained at the two different speeds was expected, however, as the data included results from two different surfaces and different tyres with different engineering properties. The results indicate that uncertainties, including the potential speed influence, account for less than $5 \%$ of the total variance $\left(\mathrm{R}^{2}=0.971\right)$, which is an excellent result. However, normally, the measurements were made at both speeds rather close in time. Therefore, we look at also how the measurements compare between the two test sections. They are not geographically very close, so it is always some time lapse between them; more than for the two speeds. The results are shown in Figure 3 (b). Also, in this case, the result is excellent. It shows that the room for texture 
influence and measurement uncertainties is less than $12 \%$ of the total variance. Of course, the different texture and unevenness must also give some significant differences between the results; thus, the uncertainty is probably (again) less than $5 \%$ of the total variance. On the other hand, admittedly, if measurements were repeated with longer times in-between, there may be influences of temperatures that are not accounted fully for.

Another check of the results against earlier research can be made by comparing our measurements with the road surface differences that would be obtained if applying an advanced rolling resistance model. The effect of road surface properties on rolling resistance can be evaluated with VETO's rolling resistance model [10]. The rolling resistance function in VETO has been updated several times; the one presented in Equation 2 and applied in this paper is found in VETO 2012.

$$
\mathrm{RRC}=\mathrm{C}_{\mathrm{R} 0}+\mathrm{C}_{\mathrm{R} 2} \times \mathrm{IRI}+\mathrm{C}_{\mathrm{R} 3} \times \mathrm{IRI} \times \mathrm{V}+\mathrm{C}_{\mathrm{R} 4} \times \mathrm{MPD}+\mathrm{C}_{\mathrm{R} 5} \times \mathrm{MPD} \times \mathrm{V}
$$

Note that the rolling resistance coefficient is dependent on the road surface parameters by both the IRI and MPD parameters, and is also affected by the speed, V. The coefficients $\mathrm{C}_{\mathrm{R} 0}$ to $\mathrm{C}_{\mathrm{R} 5}$ are determined for a given tyre. It was therefore possible to write the RRC on the DAC 16 surface as a function of the RRC on the SMA 8 as shown in Equation 3.

$$
\mathrm{RRC}_{\mathrm{DAC} 16}=\mathrm{RRC}_{\mathrm{SMA} 8}+\mathrm{C}_{\mathrm{R} 2} \times \Delta \mathrm{IRI}+\mathrm{C}_{\mathrm{R} 4} \times \Delta \mathrm{MPD}+\left(\mathrm{C}_{\mathrm{R} 3} \times \Delta \mathrm{IRI}+\mathrm{C}_{\mathrm{R} 5} \times \Delta \mathrm{MPD}\right) \times \mathrm{V}
$$

Where $\triangle \mathrm{IRI}$ is the difference in IRI between the DAC 16 surface and the SMA 8 surface, similarly $\triangle \mathrm{MPD}$ is the difference in MPD between the DAC 16 surface and the SMA 8 surface. Therefore, the RRC on the DAC 16 surface correlates to the RRC on the SMA 8 surface plus a component that is affected by the surface properties and speed. As previously discussed, the speed effect on the RRC is neglected here, therefore only the terms $C_{R 2}$ and $C_{R 4}$ remain. By 
evaluating the resulting function with typical values for $C_{R 2}$ and $C_{R 4}$ for light vehicles' tyres, equation 4 is obtained.

$$
\mathrm{RRC}_{\mathrm{DAC} 16}[\%]=\mathrm{RRC}_{\mathrm{SMA}}[\%]+0.0995
$$

Equation 4 indicates a linear relationship between the RRC of the two surfaces. Note that the expected intercept according to the approximation in equation 4 is 0.0995 while the actual intercept obtained by the linear regression is 0.1178 . This difference is explained, however, by taking into account the uncertainty in using typical values for terms $C_{R 2}$ and $C_{R 4}$, which may not be representative for the tyres tested here, yet they were the best available estimated at the moment this paper was written. The same applies for the regression slope of 0.9353 when compared to the expected slope of 1 on Equation 4. It should be noted that while the difference between the two surfaces may seem small when comparing the two test tracks, these differences become expressive when considering long driving distances. Nevertheless, Figure 3 indicates that the trailer measurements are reasonably reliable for the purposes of this paper.

\subsection{Tyre categories and speeds}

To compare the rolling resistance coefficient for different tyre categories the data was analysed by separating the results into different tyre categories and for different speeds. Figure 4 shows the rolling resistance coefficient for all tyre types at the test speeds of 50 and $80 \mathrm{~km} / \mathrm{h}$. The figure indicates that, even though the mean values differed by up to about 0.25 (RRC [\%]), there was significant overlap between the tyre categories at both tested speeds. Furthermore, the dispersion varied for each category; the highest dispersion was observed for the winter tyres category. The breakdown into different test speeds did not result in major differences, which was expected, given the tested speeds. 

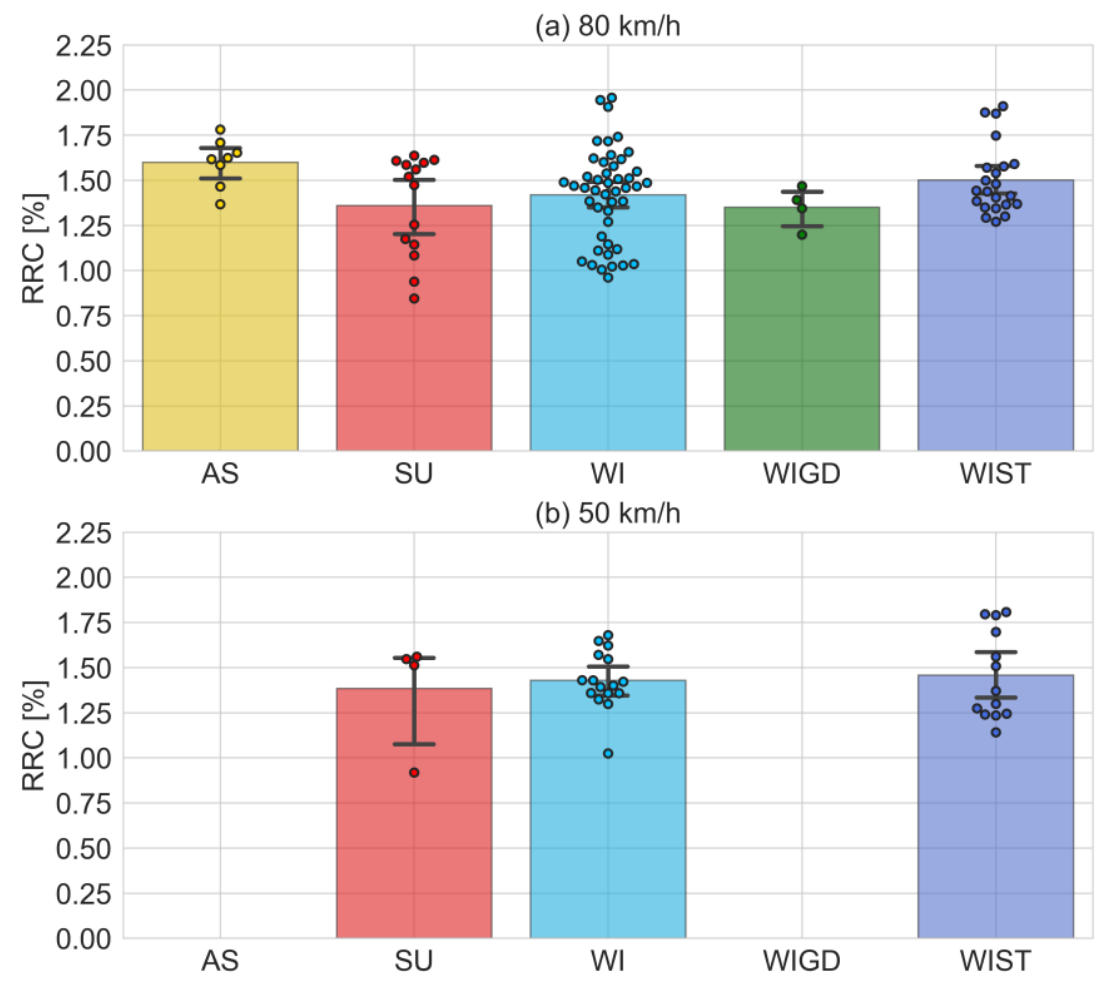

FIGURE 4 - Rolling resistance coefficients for all tyres, test tracks and for the two test speeds, (a) $80 \mathrm{~km} / \mathrm{h}$ and (b) $50 \mathrm{~km} / \mathrm{h}$, with the respective $95 \%$ confidence intervals obtained by nonparametric bootstrapping. Each circle represents one tyre. AS and WIGD tyres were only tested at $80 \mathrm{~km} / \mathrm{h}$.

\subsection{Winter tyres for northern and central Europe}

The non-studded winter tyres were previously analysed as a single group in Figure 4; however, some of those tyres were optimized for central European conditions while others were optimized for northern European conditions. By splitting the results for WI tyres into northern and central European, the different rolling resistance measurements for each test speed are presented in Figure 5. With a significance level of $5 \%$, the differences between tyres optimized for northern and central Europe were not significant at any test speed. The results also indicated 
that the dispersion was higher for tyres optimized for the northern climate in comparison to those optimized for the central European climate.
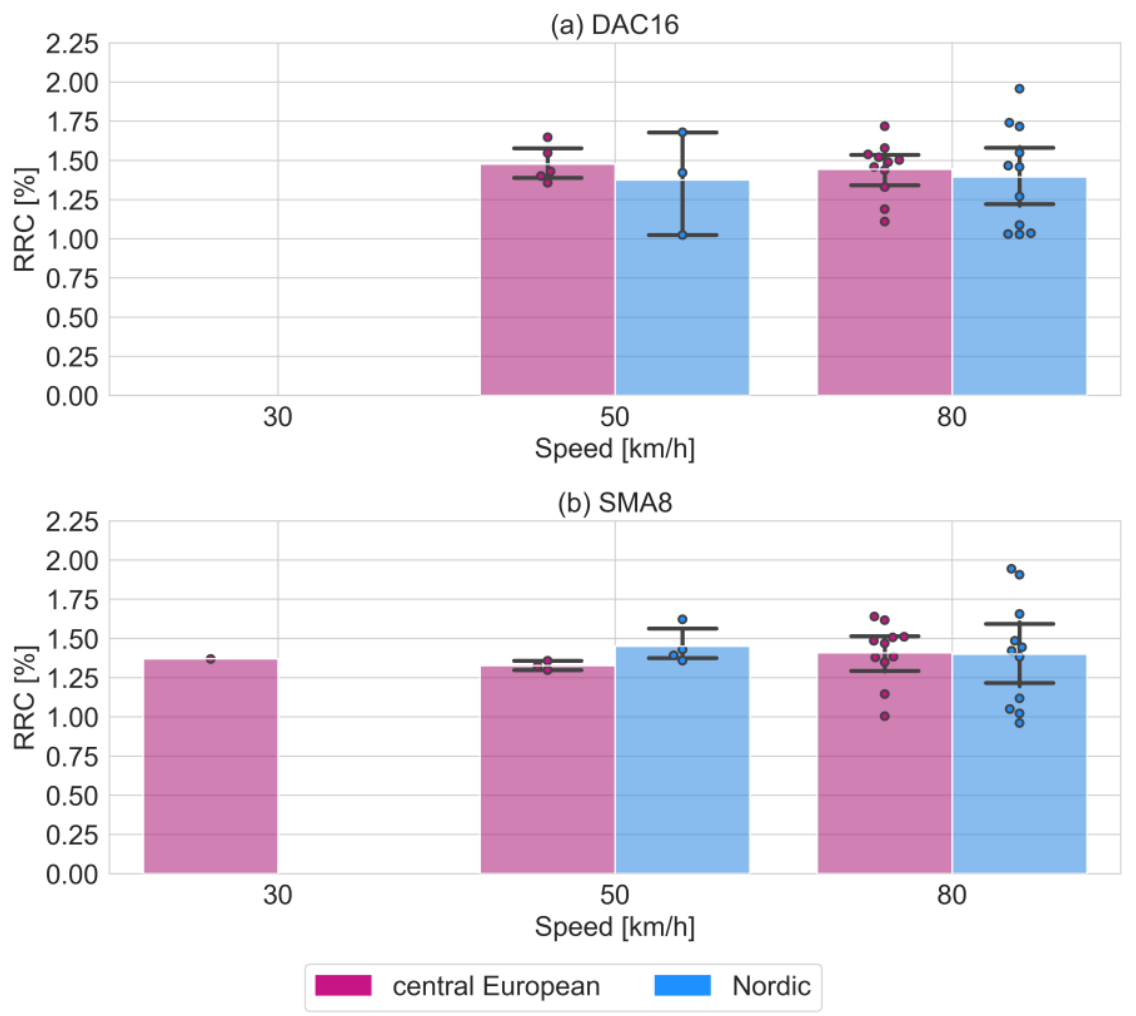

FIGURE 5 - Rolling Resistance for winter tyres optimized for northern and central European conditions (a) on the DAC 16 surface and (b) on the SMA 8 surface. Error bars indicate the $95 \%$ confidence interval obtained by non-parametric bootstrapping, for the mean value within each category and test speed. On the DAC 16 surface no tyres were tested at $30 \mathrm{~km} / \mathrm{h}$, and on the SMA 8 surface no Nordic tyres were tested at $30 \mathrm{~km} / \mathrm{h}$.

\subsection{Difference between tyres in new and used conditions}

A small sample of three winter tyres, of which one was studded, was analysed in both new and used conditions. The studded tyre had a tread depth of $10 \mathrm{~mm}$ in the new condition and $8 \mathrm{~mm}$ in the used condition. Stud protrusion was approximately $1.5 \mathrm{~mm}$ in the new and $0.5 \mathrm{~mm}$ in the used condition. Considering all the tested tyres evaluated in both new and used conditions, the tread depth decreased between 1 and $3 \mathrm{~mm}$ because of wear. Please note that worn winter tyres 
are allowed in Sweden only if tread depth exceeds $3 \mathrm{~mm}$. As the sample size was small, a more comprehensive statistical interpretation of these results is limited; however, according to Figure 6 , rolling resistance seemed to increase for tyres in used condition in comparison to their new counterparts. In Figure 6 it appears that the studded tyres give much higher rolling resistance than the non-studded tyres. However, this is only for the (single) studded tyre which was tested in both new and worn conditions, and this is not typical of the comparison between studded and nonstudded tyres (compare with Figure 4). Even though the wear process to which the tyre was subjected leads to a mass decrease, this process of wear will also lead to rheological changes of the rubber material [27]. This change is reflected by a rubber hardness increase, and rubber hardness affects rolling resistance. The change in rubber properties seem to balance out the mass reduction effect which lead to the net increase in rolling resistance.

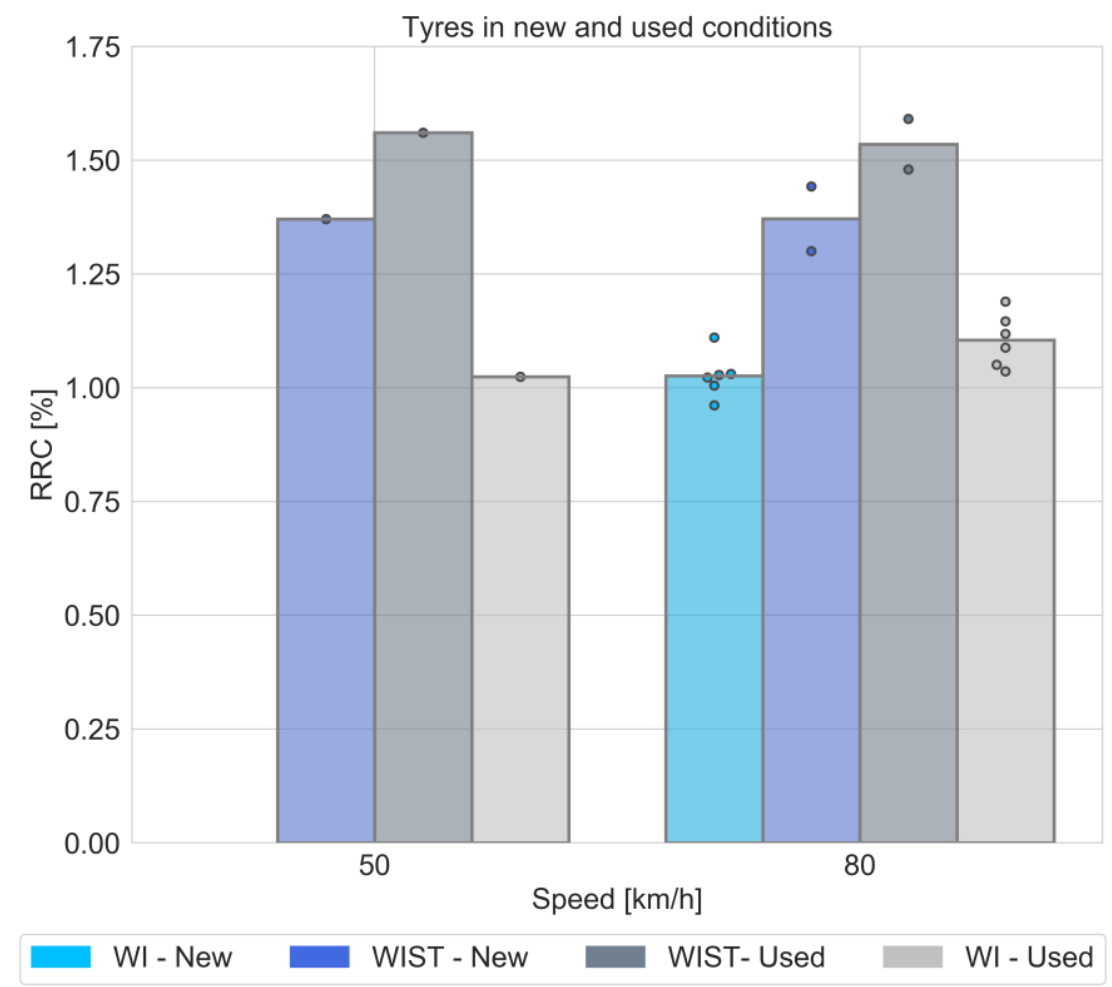


FIGURE 6 - Rolling resistance for WI and WIST tyres tested in both new and used conditions. Note that the sample size for this comparison was small. At $50 \mathrm{~km} / \mathrm{h}$, no results for WI tyres in new condition were available.

\subsection{Difference between the two test tracks}

The effect of the two test tracks is studied in this section. For this purpose, the rolling resistance results for the SMA 8 surface were subtracted from those of the DAC 16 surface to visualize the differences between tested surfaces. This means that positive values in this section indicate that the DAC 16 test section had a higher rolling resistance than the SMA 8 test section. Negative values indicate that SMA 8 had a higher rolling resistance than the DAC 16 test section. The results are presented in Figure 7 . In most cases, the $95 \%$ confidence interval for the mean encompasses zero, the only exception being the WIGD. This group had an increase of approximately 0.15 (RRC [\%]) in the rolling resistance coefficient for the DAC 16 surface in comparison to the SMA 8 surface. The other tested categories did not significantly differentiate between the two surfaces. Note, however that the dispersion within each group, and particularly for WI tyres is significant, meaning that some tyres indeed differentiate between the two surfaces by up to 0.20 (RRC [\%]). While the average result within each group indicates that on average there is no difference between the two surfaces for all groups except WIGD, many tyres within each group performed differently when comparing the RRC on the two surfaces. This indicates that differences between individual tyres in each group is more relevant than the group itself. 

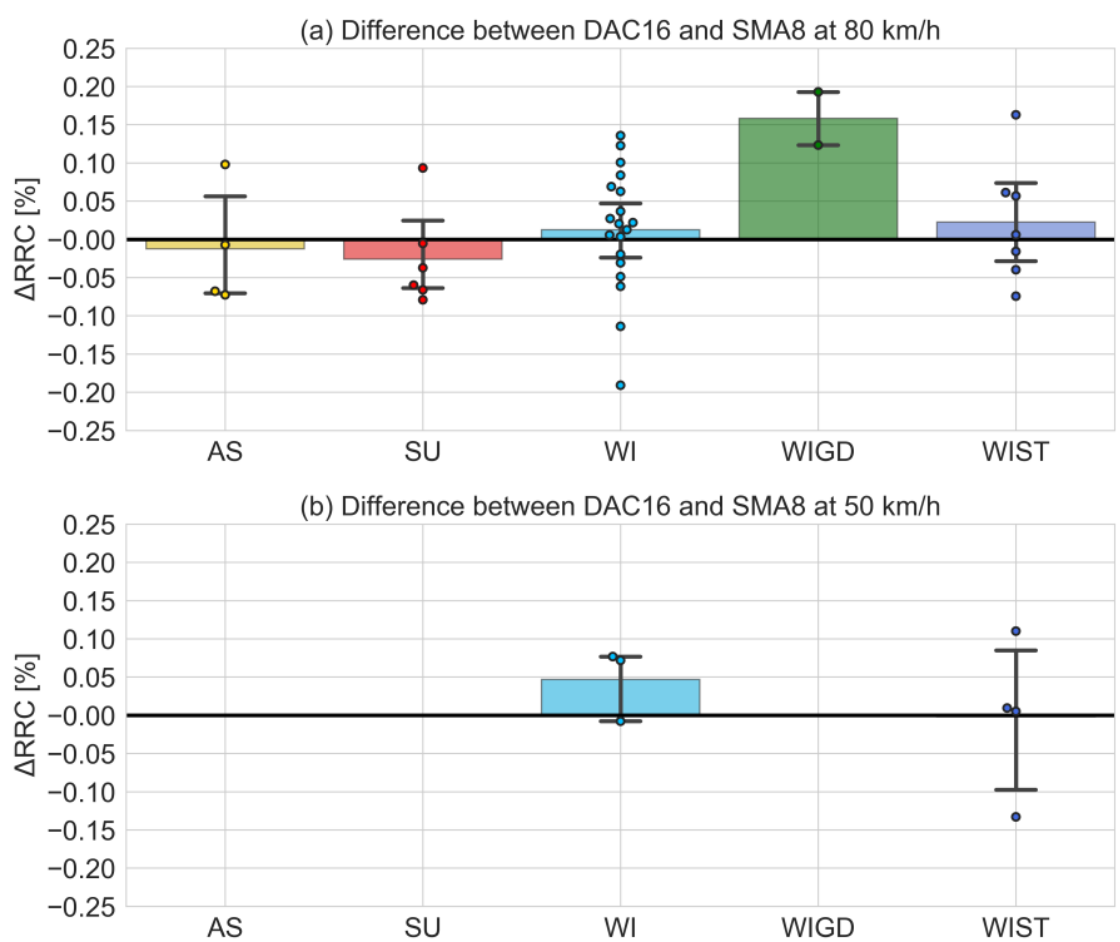

FIGURE 7 - Difference between the rolling resistance coefficients for the two test tracks for (a) $80 \mathrm{~km} / \mathrm{h}$ and (b) $50 \mathrm{~km} / \mathrm{h}$. Positive values indicate that DAC 16 had higher rolling resistance and negative values indicate that SMA 8 had higher rolling resistance. The figure also shows the 95 $\%$ confidence interval obtained by non-parametric bootstrapping for the mean value of each tyre category.

\subsection{Difference between test tracks for tyres optimized for northern and central Europe}

To further investigate the role of the two surfaces, the performance of winter tyres optimized for northern and central Europe was also compared, see Figure 8. Again, positive values indicate that the DAC 16 surface had a higher rolling resistance and negative values indicate that the SMA 8 had a higher rolling resistance. Differences were observed only at 50 $\mathrm{km} / \mathrm{h}$. At this speed the tyres for central Europe resulted in a higher rolling resistance on the DAC 16 surface; however, the RRC difference was only about $0.07 \%$. The other tested conditions were insensitive with respect to the tested surface. Similar to the previous section, the results 
seem to indicate that differences between individual tyres is more relevant than differences between the different groups.

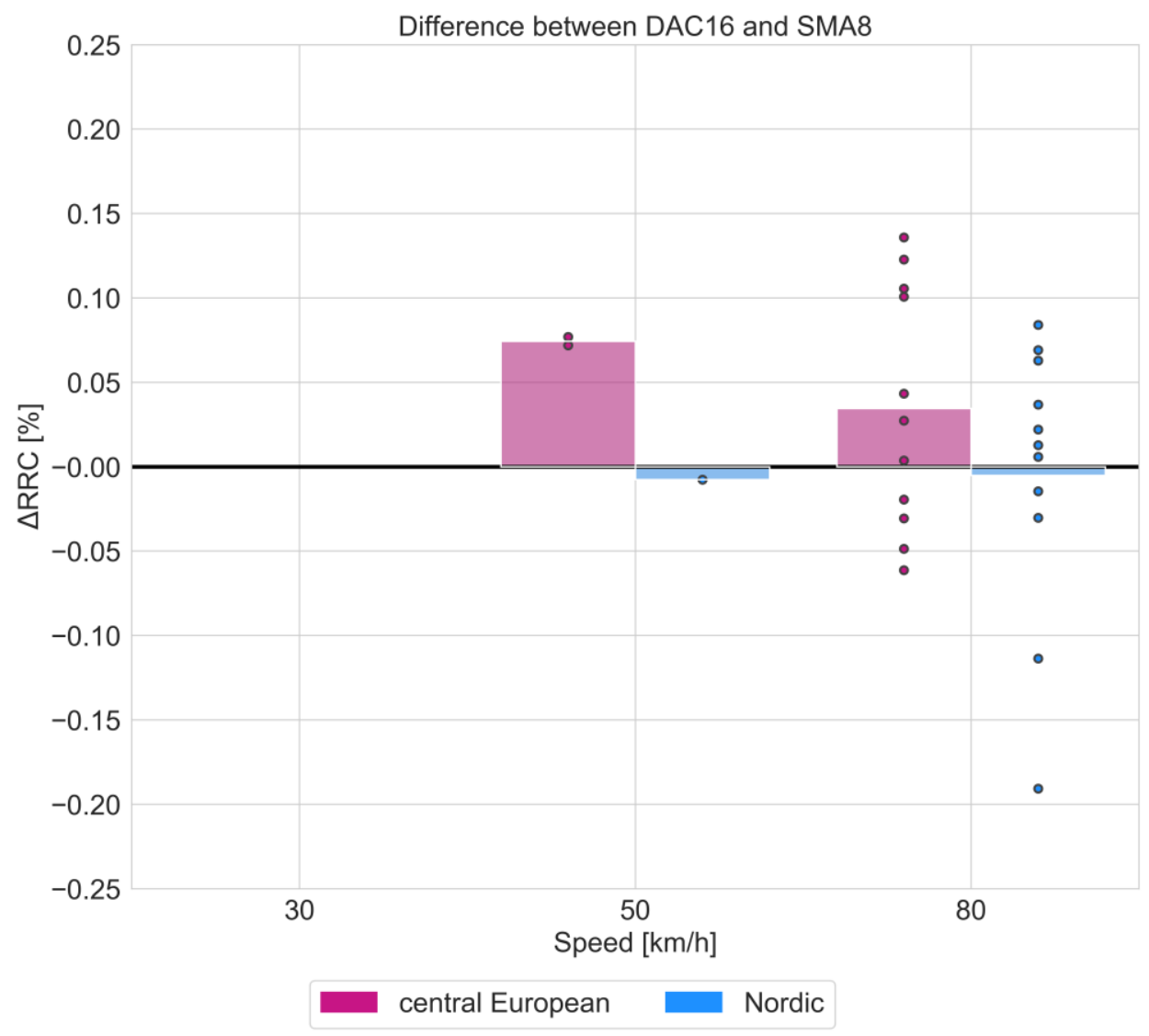

FIGURE 8 - Difference between the two test surfaces for winter tyres optimized for Nordic and central European climates.

\subsection{The effect of removing the studs}

A closer look at the effects of studs is presented in Figure 9. The rolling resistance of two tyres which are fitted with studs are compared to the case of two identical tyres not fitted with studs (the latter tyres were removed from the production of studded tyres just before the studs were mounted). Therefore, the only nominal difference between the tyres was indeed due to the insertion of the studs. These studs weighed on average about $1 \mathrm{~g}$ and with 190 studs per tyre, this 
gives an increased weight of only around $0.2 \mathrm{~kg}$ [28]. Compared to the total weight of a light vehicle tyre, approximately 7 to $10 \mathrm{~kg}$, the extra weight effect of the studs is marginal. The results indicated that rolling resistance decreased at $80 \mathrm{~km} / \mathrm{h}$ when the studs were not present. Note that the sample size in this comparison was small and the difference (0.06 in RRC) could well be due to chance or measurement uncertainties.

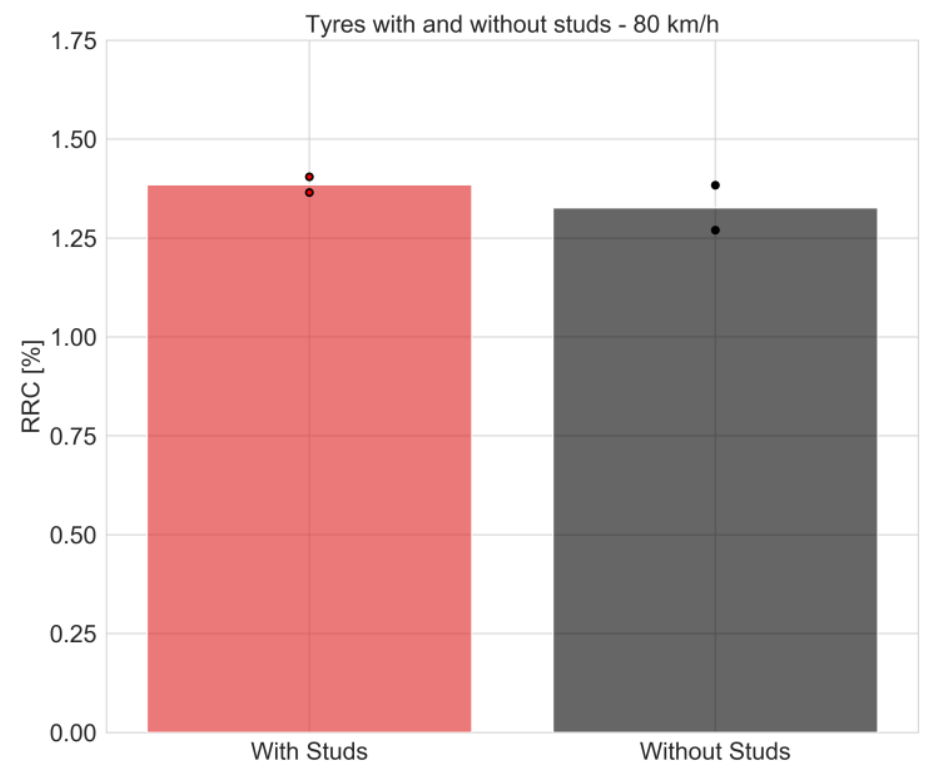

FIGURE 9 - Comparing two tyres fitted with studs and two other tyres without studs. Except for the studs, the tyres were nominally identical.

\subsection{Measured values and labelled values}

The results obtained from the two road surfaces were also compared to the labelled values for each of the tested tyres, see Figure 10. The tyre labelled value is regulated by the European Parliament and Council Regulation number 1222/2009 [29]. The label values are given in classes from $\mathrm{A}$ to $\mathrm{G}$, but in this case, we have used the RRC mid-value for each class. 
As Figure 10 shows, no significant correlation was found between the labelled energy values and the measured RRC values on the road sections. Note that WIGD and WIST are not included in this section as the current labelling regulations do not apply to either retreaded or studded tyres.
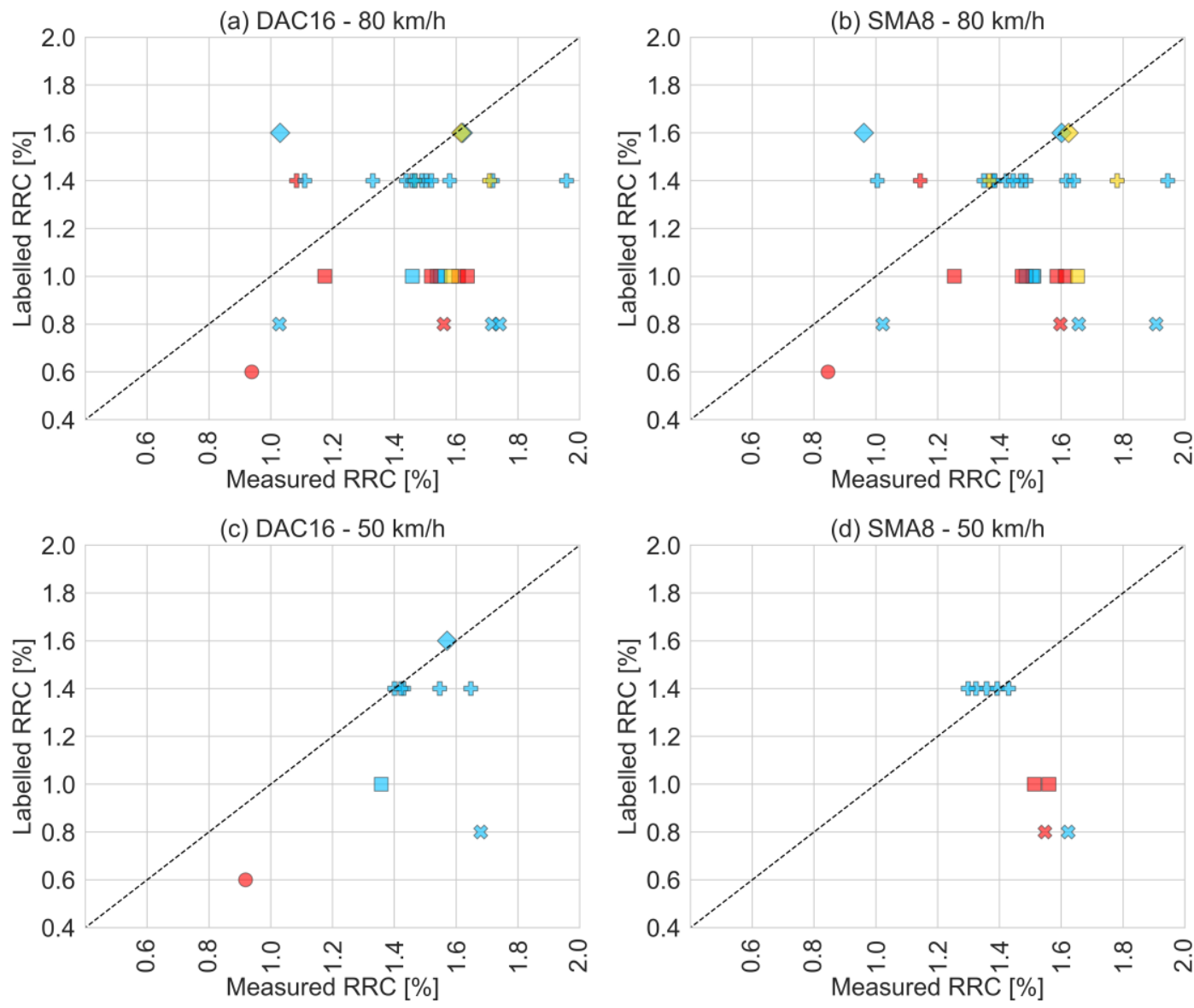

Type

$$
\text { AS } \quad-\text { SU } \bullet W I
$$$$
\text { Fuel_efficiency }
$$

- A

FIGURE 10 - Road measured versus labelled rolling resistance values for each tyre, test section and speed: (a) DAC 16 at $80 \mathrm{~km} / \mathrm{h}$, (b) SMA 8 at $80 \mathrm{~km} / \mathrm{h}$, (c) DAC 16 at $50 \mathrm{~km} / \mathrm{h}$, (d) SMA 8 at $50 \mathrm{~km} / \mathrm{h}$. An ideal equality between the measured and labelled values is represented by the $45^{\circ}$ dashed lines.

\subsection{Drum results}


Some of the tested tyres were also evaluated on drums, allowing a comparison with the road results. Three different conditions were available on the drum results, namely: (i) ECE R117 Safety Walk, (ii) ECE R117 - SMA 8, (iii) TUG (procedure) - SMA 8. The results shown in Figure 11 indicate that the road results were usually higher than the corresponding values measured on the drum and also covered a much wider range. No significant correlation was found between measurements on the road and on the drum, given a $95 \%$ confidence interval.
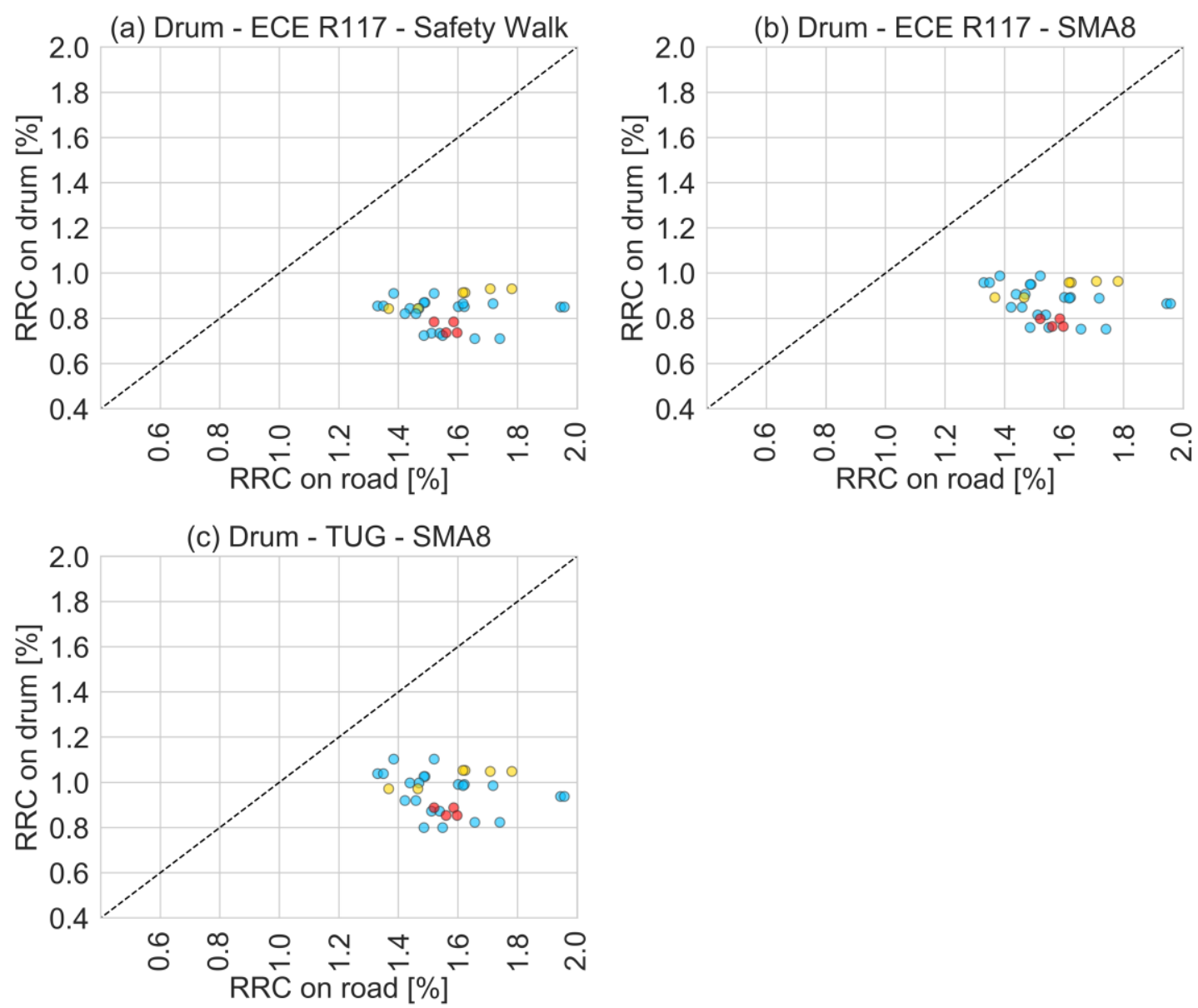

$$
\text { AS }
$$$$
\text { SU }
$$$$
\text { WI }
$$

FIGURE 11 - Drum measured versus road measured rolling resistance values for the (a) Safety Walk drum surface (b) SMA 8 surface under ECE R117 conditions and (c) SMA 8 surface under 
TUG conditions. An ideal equality between measured and labelled values is represented by the $45^{\circ}$ dashed lines.

\subsection{Drum measurements and labelled values}

The drum results were also compared to the labelled values; the latter determined from similar drum measurements. These results have a better overall correlation to the labelled values. The ECE R117 procedure with a Safety Walk (sandpaper) surface led to the highest Pearson's correlation coefficient, 0.88 , followed by the same conditions with a replica SMA 8 at 0.85 , and the TUG procedure at 0.83 ; see Figure 12 .

It is notable that, although the correlation is high, the slope of the regression line is far from 1.0. The range between the labelled values is much larger than the range of the drum measurements (Figure 12). This is peculiar and the authors cannot offer any explanation. 

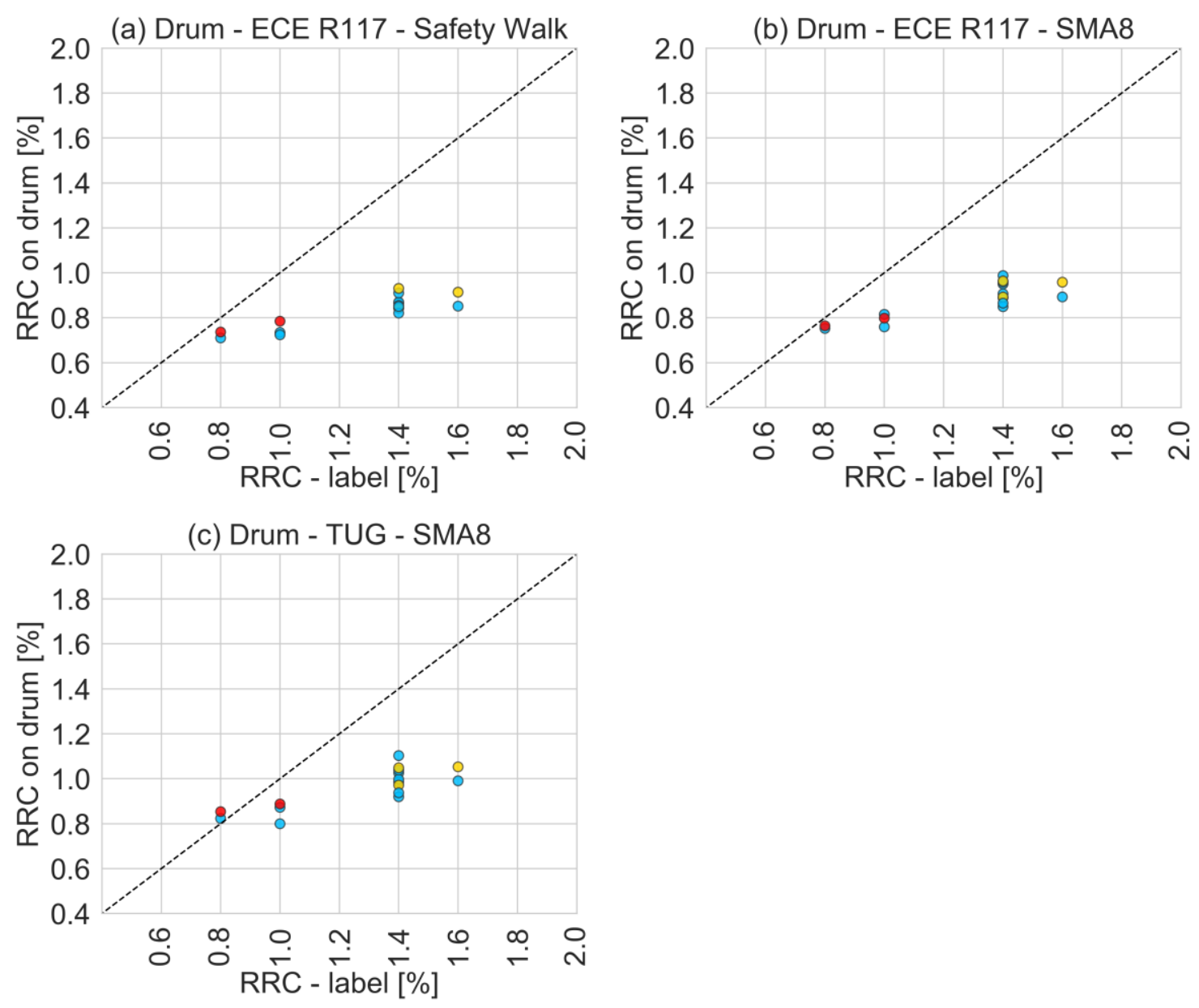

$$
\text { AS SU WI }
$$

FIGURE 12 - Rolling resistance measured on drum versus labelled values for drum measurements with (a) Safety Walk under ECE R117 conditions, (b) SMA 8 under ECE R117 conditions, (c) SMA 8 under TUG conditions. An ideal equality between the measured and labelled values is represented by the $45^{\circ}$ dashed lines.

\subsection{Rolling resistance and noise at different frequencies}

The results for rolling resistance were compared to noise results with the same tyres and on the same test tracks. Table 4 shows the Pearson's correlation for different frequency ranges and rolling resistance results. The low frequency range was chosen as the spectral range that is mostly dominated by texture interaction and vibrational mechanisms. The middle frequency was selected 
to encompass frequencies affected by noise absorption mechanisms. Finally, the high frequency range was selected to encompass the frequencies related to aerodynamic noise generation mechanisms [30]. No significant correlations were obtained, irrespective of frequency, pavement and test speed.

TABLE 4 - The Pearson's correlation coefficients between rolling resistance and tyre/road noise with the CPX method for each speed and test section.

\begin{tabular}{|c|c|c|c|c|}
\hline Surface & \multicolumn{2}{|c|}{ DAC 16 } & \multicolumn{2}{c|}{ SMA 8 } \\
\hline $\begin{array}{c}\text { Speed [km/h] } \\
\text { Low frequency CPX (200 Hz - 800 } \\
\mathrm{Hz})\end{array}$ & $15 \%$ & $13 \%$ & $4 \%$ & $18 \%$ \\
\hline $\begin{array}{c}\text { Middle frequency CPX (1 kHz - } \\
\mathrm{kHz})\end{array}$ & $5 \%$ & $16 \%$ & $6 \%$ & $14 \%$ \\
\hline $\begin{array}{c}\text { High frequency CPX (2.5 kHz - } 10 \\
\mathrm{kHz})\end{array}$ & $18 \%$ & $19 \%$ & $17 \%$ & $12 \%$ \\
\hline
\end{tabular}

\section{Discussion}

The results of this study suggests some interesting and some strange observations, listed and discussed critically in the following.

Tyre/road rolling resistance is an interaction between tyre and road surface, mainly excited by deformations in the tyre, and when the drum surface is much smoother than a real road surface, one important type of tyre deformations is totally absent; thus, the interaction is essentially "onesided". If the drum has a replica road surface, the authors consider it as better; yet, there is a drum curvature which gives abnormal tyre deformation.

Rolling resistance of studded winter tyres is not consistently and significantly higher than that of non-studded tyres. Neither the results presented in Fig. 4 nor in Fig. 9 suggest that rolling resistance is higher for studded than non-studded winter tyres. This indicates that there is one less environmental disadvantage of such tyres. It is however surprising as it was shown in [17] that 
studded tyres emitted higher noise than non-studded tyres also at lower frequencies, while it is known that the lower frequencies are indications of increased vibrational mechanisms; something that should create higher rolling resistance. Table 4 is also inconsistent with that assumption. This needs further studies in order to explain how this may happen.

The Green Diamond tyres (WIGD) showed a relatively low rolling resistance. This means that these tyres offers not only acoustical advantages [17] as well as is less expensive to purchase (as a retreaded tyre), but also offers good fuel economy. Since it is a result of recycling and less fuel consumption means less $\mathrm{CO}_{2}$ emissions, the environmental benefits are consistently good.

The "all-seasons" tyres (AS) tested here appear to have relatively high rolling resistance. As these tyres are a compromize between summer and winter performance, i.e. they should offer reasonable performance on both dry and wet summer roads and on snowy and icy winter roads, intended to make it feasible to use the same tyres all the year; at least in climates that are not too extreme. The tyres tested here might have had to sacrifice some rolling resistance performance for this purpose. This is not unexpected since AS tyres must satisfy more performance variables than specialized tyres, and the more variables that shall be satisfied generally means that it has to sacrifice something else. This can futher be seen in figure 4.

In Figure 12(b) the drum RRC values range between 0.75 and 1.00 , while the road RRC values range between 1.3 and 1.8. The range is twice as large on the road than on the drum (with nominally similar replica surface). Note that tyre loads are the same. There is no correlation between tyre RRC on drum vs road. Although on the road one has far from ideal conditions and the road also has unevenness that the drum does not have, but the differences are too large to explain. This question needs to be addressed later. Figure 15(a) indicates a similar effect as 
mentioned above, namely that the range of RRC in drum measurements is much lower that the range of RRC based on the labelling values. While the TUG drum measurements (for the sandpaper surface which may also be used in the labelling) cover a RRC value range of 0.7 to 0.9, the labelling RRC values are between 0.8 and 1.6. This is a dramatic difference of four times larger range in the labelling than the drum measurements, and this is far too high to be correct. Note that tyre loads, inflation and drum surfaces and the measurement methods as a whole should are essentially the same. Yet, the correlation coefficient between the two sets of data is as high as 0.88. This means that neither data can be ignored. But the dramatic difference in range is difficult to explain and needs further investigation.

The possibility of poor road or drum measurements of RRC: The problems mentioned above gave the authors reason to check if something serious could have been wrong with the trailer rolling resistance measurements. The RRC results did not seem to correlate with neither the drum measurements, nor the labelling values. However, the range in the road RRC measurements was essentially the same as in the labelling RRC data. Further, as shown in Figure 3, the repeatability seems to be good. The same seems to be the case for the drum measurements. The measurements with the ECE R117 and the TUG procedures were done independently and the results was that the two procedures gave almost identical correlation between the RRC values determined by the two procedures.

\section{Conclusions}

More than 500 rolling resistance measurements for different types of tyres on two different road surfaces were analysed in this paper, in addition to rolling resistance measurements

on a drum facility. The rolling resistance of the tyres measured on roads indicated a considerable 
overlap between the different tyre categories. Some tyres presented different results depending on the test track. Even though the average for each tyre group was not significantly affected by testing on different surfaces, the variation within each group was substantial. Differences between individual tyres seem to be more relevant than the tyre type itself.

The effect of removing the studs was also evaluated, indicating that rolling resistance was somewhat reduced, but when looking at winter tyres with and without studs, the difference between the two groups was insignificant. More tests are required to achieve statistically significant results for the effect of the studs.

When comparing measurements on roads with the labelled values, the average results from road measurements were higher than the labelled values. The correlation between the road measurements and the labelled values was insignificant.

The drum results led to lower RRC values in comparison with road conditions and did not lead to any significant correlations. Rather high correlations were found, however, when comparing labelled and drum measurement results.

Correlations between rolling resistance measured with the trailer method and tyre/road noise measured with the CPX method on the same pavements were analysed, but no significant correlation was found between the two measurements. A more systematic investigation of the correlation between rolling resistance and tyre/road noise would be of interest to try to correlate noise at different frequencies to rolling resistance.

A major conclusion of this study is that the energy labelling of individual tyres could not be reproduced in road measurements by the trailer method. Since the latter are assumed to be more representative to what happens in real traffic, the results suggest that one must look closer at the measurement methods with the aim that road and laboratory measurements correlate well. 
This is an important issue for the consumers (including vehicle manufacturers) who would use the labelling values when they select new tyres.

\section{Acknowledgements}

The VTI project on winter tyres was led by Dr Mattias Hjort at VTI and was financed by the Swedish Transport Administration. The project also included comprehensive friction measurements (by Dr Hjort), not reported here. The first author's work was part of his PhD programme, which is sponsored by the Swedish Transport Administration and by VTI. The rolling resistance measurements were performed by Prof. Jerzy A. Ejsmont and Dr Beata Świeczko-Żurek at the Technical University of Gdansk (TUG) in Poland. Dr Mikko Liukkula and Nokian Tyres Finland contributed with some of the tested tyres from Nokian.

\section{References}

[1] Carlson A, Karlsson R, Eriksson O. Energy use due to traffic and pavement maintenace: The cost effectiveness of reducing rolling resistance. Linköping, Sweden: Statens vägoch transportforskningsinstitut (VTI); 2016. VTI notat 9A-2016.

[2] Gent AN, Walter JD. The pneumatic tire. Washington DC, USA: NHTSA; 2005.

[3] Wang J, Besselink I, Nijmeijer H. Electric Vehicle Energy Consumption Modelling and Prediction Based on Road Information. World Electric Vehicle Journal. 2015;7(3):447.

[4] Hammarström U, Karlsson R, Sörensen H. Road surface effects on rolling resistance: coastdown measurements with uncertainty analysis in focus. Linköping, Sweden: Statens väg- och transportforskningsinstitut (VTI); 2009. 
[5] Carlson A, Vieira T. Effekten på rullmotstånd av nederbörd på vägytan: en kunskapsöversikt. Linköping: Statens väg- och transportforskningsinstitut (VTI); 2018. VTI repport 927 (In Swedish).

[6] Gustafsson M, Berglund CM, Forsberg B, Forsberg I, Forward S, Grudemo S, et al. Effekter av vinterdäck: En kunskapsöversikt. Linköping, Sweden: VTI; 2006. VTI repport 543 (In Swedish).

[7] Angelov EI. The studded tire - a fair bargain? Master in Environmental Economics. Uppsala, Sweden: Swedish University of Agricultural Sciences; 2003.

[8] Mitschke M, Wallentowitz H. Dynamik der Kraftfahrzeuge. 4 ed. Berlin: Springer; 2004 (In German).

[9] Carlson A. Rullmotstånd : vägytans egenskaper och dess inverkan. Linköping: Statens väg- och transportforskningsinstitut; 2017 2017. Report No.: 03476030 (ISSN) (In Swedish).

[10] Hammarström U, Eriksson J, Kalrsson r, Yahya M-R. Rolling resistance model, fuel consumption model and the traffic energy saving potential from changed road surface conditions. Linköping, Sweden: VTI; 2012. VTI rapport 748A.

[11] Ejsmont JA, Ronowski G, Świeczko-Żurek B, Sommer S. Road texture influence on tyre rolling resistance. Road Materials and Pavement Design. 2017;18(1):181-98. doi: $10.1080 / 14680629.2016 .1160835$

[12] Papaioannou P, Schmidt B, Dyre JC. Transport Research Arena 2012CO2 Emission Reduction by Exploitation of Rolling Resistance Modelling of Pavements. Procedia Social and Behavioral Sciences. 2012;48:311-20. 
[13] Vieira T, Sandberg U, Erlingsson S. Negative texture, positive for the environment: effects of horizontal grinding of asphalt pavements. Road Materials and Pavement Design. 2019:1-22. doi: 10.1080/14680629.2019.1610476

[14] Goubert L, Do M-T, Bergiers A, Karlsson R, Sandberg U. Project ROSANNE: State-ofthe-art concerning texture influence on skid resistance, noise emission and rolling resistance. 2014.

[15] Ejsmont J, Taryma S, Mioduszewski P. Metodyka pomiaru oporu toczenia opon do samochodów osobowych i dostawczych - część 1: Metoda narastających prędkości. Gdansk, Poland: Technical University of Gdansk; 1995 (In Polish).

[16] International Organization for Standardization. ISO 11819 - 2: 2017. Acoustics Measurement of the influence of road surfaces on traffic noise - Part 2: The Closeproximity method. Geneva, Switzerland: International Organization for Standardization; 2017.

[17] Vieira T, Sandberg U, Erlingsson S. Acoustical performance of winter tyres on in-service road surfaces. Appl Acoust. 2019;153:30-47.

[18] ASTM International. ASTM F 2493-14: 2014. Standard Specification for P225/60R16 $97 S$ Radial Standard Reference Test Tire.Pennsylvania, United States: ASTM International; 2014.

[19] United Nations Economic Commissions for Europe (ECE). ECE R117 Rev 2: 2011. Uniform provisions concerning the approval of tyres with regard to rolling sound emissions and to adhesion on wet surfaces and/or to rolling resistance.Geneva, Switzerland: 2011. 
[20] International Organization for Standardization. ISO 10844: 1994. Acoustics -Specification of test tracks for the purpose of measuring noise emitted by road vehicles.Geneva, Switzerland: International Organization for Standardization; 1994.

[21] International Organization for Standardization. ISO 13473-1: 1997. Characterization of pavement texture by use of surface profiles - Part 1: Determination of Mean Profile Depth.Geneva, Switzerland: International Organization for Standardization; 1997.

[22] Swedish Standards Institute. SS-EN 13036-5: 2019. Road and airfield surface characteristics - Test methods - Part 5: Determination of longitudinal unevennness indices.Stockholm, Sweden: Swedish Standards Institute; 2019.

[23] Gültlinger J, Gauterin F, Brandau C, Schlittenhard J, Wies B. Investigations of Road Wear Caused by Studded Tires. Tire Science and Technology. 2014;42(1):2-15.

[24] Zöller M, Haider M. State of the art on rolling resistance measurement devices. 2014.

[25] Ronowski G. Design and Calibration of Rolling Resistance Test Trailer R2Mk.2. IOP Conference Series: Materials Science and Engineering. 2016;Vol. 148(1):pp. 1-11.

[26] Ejsmont J, Taryma S, Ronowski G, Swieczko-Zurek B. Influence of temperature on the tyre rolling resistance. International Journal of Automotive Technology. 2018;19(1):4554.

[27] Sandberg U, Glaeser K-P. Effect of tyre wear on noise emission and rolling resistance. Inter-Noise; Shanghai, China: Chinese Academy of Sciences. Institute of Acoustics; 2008.

[28] Gustafsson M, Eriksson O. Emission of inhalable particles from studded tyre wear of road pavements. Linköping, Sweden: Statens väg- och transportforskningsinstitut (VTI); 2015. VTI repport 867A. 
[29] European Parliament and Council. Regulation (EC) No 1222/2009: Labelling of tyres with respect to fuel efficiency and other essencial parameters. Official Journal of the European Communities; 2009.

[30] Sandberg U, Ejsmont JA. Tyre/road noise reference book. Kisa, Sweden: Informex; 2002. Pp. 616. 